\title{
Performance Analysis of Optically Semi-Transparent Material Packed-Bed Solar Air Heater
}

\author{
Vimal Ku. Chouksey* and S.P. Sharma \\ Department of Mechanical Engineering, N.I.T. Jamshedpur, Jharkhand, India \\ E-mail: *vimalkumarchouksey@ gmail.com; Phone no.- +917870527386
}

Received 10 October 2016, Revised 30 December 2016, Accepted 31 December 2016

\begin{abstract}
This paper deals with theoretical analysis of performance of solar air collector having its duct packed with optically semitransparent materials. The heat transfer equations for two dimensional fully developed fluid flows under quasisteady state conditions have been developed in order to analyze the thermal, thermo-hydraulic and exergy performance and to study the effect of system and operating parameters. A computer programme is developed in $\mathrm{C}^{++}$ language to estimate the temperature rise of entering air for evaluation of performance by solving the governing equations numerically using relevant correlations for heat transfer coefficient for packed bed systems. Results of air temperature rise and thermal efficiency obtained from the analysis have been compared with available experimental results and results are found fairly in closed agreement. It has been found that there is considerable enhancement in thermal efficiency with packed bed collector. Effect of total bed depth on efficiency show that there is an upper limiting value of total bed depth beyond which the thermal efficiency begins to fall again and this type of characteristics behavior is observed at all mass flow rate. It is also noticed that there exists an optimal value of effective and exergy efficiencies for a given mass flow rate.
\end{abstract}

Keywords: Solar energy; optically semi-transparent packed bed; solar air heater; plane collector.

\section{Introduction}

The applications of porous materials in air flow channels has been recommended and successfully adopted for enhancement of heat transfer by several investigators [14]. The shape of packing elements in packing beds can range from spheres, solid and hollow cylinders of various aspect ratios, woven-wire mesh, brick arrangements, and metallic plate matrices to proprietary packings, such as Berl saddles, Pall rings and Intalos rings. A number of correlation for the determination of heat transfer coefficient have also been put forward in terms of bed and fluid flow parameters like equivalent particle diameter of packings, porosity, modified Reynolds number and Prandtl number.

The use of porous materials, such as slit-and-expanded aluminum foil matrix [5-7], wire-screen matrix [8-9], hollow spheres [10], iron chips [11,12] as heat absorbing media in air-cooled solar collector has also been proposed and tested in order to improve the collector performance. Mishra and Sharma [13] tested the performance of solar air heater having its bed packed with iron-chips, aluminum chips and pebbles and reported that the performance of plane collectors improves appreciably by packing the duct with blackened metallic materials. The use of crushed glass matrices as the heat-absorbing media in air heating solar collectors has been investigated by Collier [14]. Hastani et al. [15] reported that solar air heaters packed with semitransparent materials like glass beads or glass tubes had higher efficiency of energy collection in comparison to a usual flat-plate collector.

Packed bed with optically semi-transparent materials absorbs solar radiation "in depth" and has high ratio of heat transfer area to volume and high heat transfer capability, resulting in relatively low absorber temperatures. This will decrease the heat losses from absorber to ambient and hence result in an increase in the efficiency of the collectors. Demirel and Kunc [16] compared the performances of two types of solar air heaters: one with the packed airflow passage filled with Raschig rings and the other without the packing, and found that the packing increased the thermal efficiency considerably. This is mainly because the packing breaks the resistance film underneath the plate and causes a better radial dispersion. Demirel [17] reported that the wall-to-gas heat transfer in a rectangular duct with asymmetric heating increased by a factor of three after introducing packing into the flow passage.

Demirel et al. [18] estimated the entropy generation of a fully developed forced convection in large rectangular packed ducts with asymmetric heating, which resembles the packed solar heaters. Ozturk et al. [19] conducted a theoretical study on thermal analysis of packed-bed solar air heaters. Demirel and Kahraman[20] calculated the entropy generation due to heat transfer for fully developed, forced convection flow in a large rectangular duct, packed with spherical particles, with constant heat fluxes applied to both the top (heated) and bottom (cooled) wall. This approach produces workable designs, but not necessarily those with the highest possible thermodynamic efficiencies.

Sharma et al. [21] experimentally investigated the thermal performance of solar air heater having its duct packed with blackened wire-screen matrices and reported that the improvement in performance is strong function of system and operating parameters. 
Table 1: Specifications of glass beads matrices used [14,15].

\begin{tabular}{|c|c|c|c|c|}
\hline $\begin{array}{c}\text { Packed } \\
\text { material }\end{array}$ & $\begin{array}{c}\text { Diameter of packing } \\
\text { material, } \mathbf{D}_{\mathbf{p}} \\
{[\mathrm{mm}]}\end{array}$ & $\begin{array}{c}\text { Porosity } \\
\mathbf{p}\end{array}$ & $\begin{array}{c}\text { Surface area/ Volume of } \\
\text { packing material, } \mathbf{A}_{\mathbf{p}} / \mathbf{V}_{\mathbf{p}} \\
{\left[\mathrm{m}^{2} \mathrm{~m}^{-3}\right]}\end{array}$ & $\begin{array}{c}\text { Extension } \\
\text { coefficient } \boldsymbol{\beta} \\
{\left[\mathrm{m}^{-1}\right]}\end{array}$ \\
\hline \multirow{3}{*}{$\begin{array}{c}\text { Glass } \\
\text { beads }\end{array}$} & 3.4 & 0.41 & 1140 & 70 \\
\cline { 2 - 5 } & 5.2 & 0.43 & 430 & 60 \\
\cline { 2 - 5 } & 10.0 & 0.46 & 360 & 50 \\
\hline
\end{tabular}

Comparative theoretical performance analysis of solar air heater packed bed with different materials like cylinder, ring, sphere and crushed materials; and without packing in the flow passage were done by Choudhary and Garg [22]. Ozturk and Demirel [23] experimentally investigated the thermal performance of solar air heater having its flow channel packed with Rasching rings. They found that the energy and exergy efficiencies of the packed bed solar air heater were increased as the outlet temperature of heat transfer fluid was increased. Various configurations of copper screen meshes to identify the preferable orientation for maximizing thermal performance were experimentally investigated by Tian et al. [24] under steady state forced air convection and reported that the overall heat transfer depends on porosity and surface area density but weakly on orientation.

Varshney and Saini [25] have experimentally investigated the heat transfer and flow friction characteristics of solar air heater having its duct packed with wire mesh screen and the correlations have been developed for the Colburn $\mathrm{j}$ factor and friction factor for porosity range of 0.89 to 0.96 and packing Reynolds number range from 182 to 1168 .

Similar type of experimental investigations on wire mesh screen were reported by Thakur et al. [26] and Prasad et al. [27] for different porosities range i.e. 0.667 to 0.880 and 0.599 to 0.816 respectively. Aldabbagh et al. [28] experimentally investigated the thermal performance of double pass steel wire screen packed bed solar air heater and reported that the efficiency of the double pass is found to be higher than the single pass. The counter and parallel flow packed bed solar air heaters are investigated theoretically and experimentally by Dhiman et al. [29]. The effect of air mass flow rates and bed porosity on the thermal and thermo-hydraulic efficiencies of the counter and parallel flow packed bed solar air heaters are investigated. Verma and Varshney[30] developed a mathematical model to investigate the effect of system and operating parameters on the thermal and thermo-hydraulic performance of wire screen packed bed solar air heater for high (0.887-0.958) and low (0.599-0.729) porosity range.
Chouksey and Sharma [31] investigated theoretically the thermal performance characteristics of solar air heater having its duct packed with blackened wire screen matrices. A computer program is developed in $\mathrm{C}^{++}$language to estimate the temperature rise of the entering air for evaluation of thermal efficiency by solving the governing equations numerically using relevant correlations for heat transfer coefficient for packed bed systems. The percentage deviation between the analytical and available experimental values of the dimensionless air temperatures of air and thermal efficiency have been found to be in the range of 7.18 to -9.83 and 7.20 to -9.65 respectively.

In this paper a solar air heater having its duct packed with optically semi-transparent glass beads matrices listed in Table 1, has been analyzed to develop relationship between system and operating parameters on the thermal, thermo-hydraulic and exergy performance of the system. The choice of such packing elements has been made due to their easy availability in standard sizes and small additional expenditure.

\section{Theoretical Analysis}

The solar air heater having its duct packed with optically semi-transparent spherical glass beads matrices as shown in Figure 1 has been considered. The channel of width $\mathrm{W}$, depth $\mathrm{D}$ and length $\mathrm{L}$ and having one glass cover, is uniformly heated from top by solar radiations transmitted through glass cover.

These transmitted radiations heat the packed bed matrix which in turn heat the air flowing through the channel with a constant and uniform velocity, $\overline{\mathrm{u}}$ in $\mathrm{x}$ direction. The air then emerges out of the channel at higher temperature. The parameters involved in the heat exchange process have been indicated in Figure 1 . Here $\mathrm{R}_{\mathrm{y}}$ and $\mathrm{I}_{\mathrm{y}}$ represent respectively the value of radiosity and irradiation as a function of vertical distance parameter $\mathrm{y} . \mathrm{R}$ and $\mathrm{I}, \mathrm{R}_{1}$ and $\mathrm{I}_{1}, \mathrm{R}_{2}$ and $\mathrm{I}_{2}$ are respectively radiosities and irradiation at upper and inner surface of glass and at the absorber plate respectively.

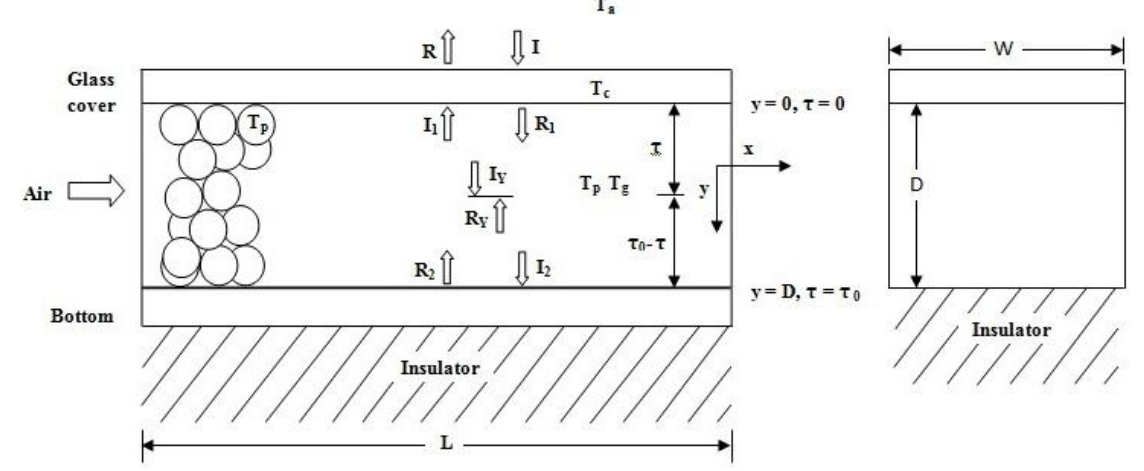

Figure 1. Optically semi-transparent packed bed solar air heater. 


\subsection{Heat Transfer Mechanism in Packed Bed Solar Air Heater}

The transfer of heat in the packed bed solar air heater takes place by simultaneous radiation, convection and conduction. The mechanism of heat transfer is discussed below:

\subsubsection{Radiation}

A fraction of the solar radiation at incident angle to glass cover is absorbed, another part is reflected and scattered while the balance is transmitted. In such a system, radiation heat exchange occurs between the solid and the glass cover, between adjacent voids in the bed, between contact surface of two solids, between the solid and fluid, between the solid and bottom absorber plate and between the glass cover and environment.

In order to account for radiation heat transfer in the energy balance equations following assumptions have been made.

(i) The incident radiation is absorbed exponentially in depth, with an extinction coefficient which is fairly constant $[5,8]$.

(ii) The packed bed is an isotropically homogeneous semi-transparent (allowing light to pass through diffusely) bed $[5,8]$ for incident radiation.

(iii) The effect of scattering is negligibly small.

(iv) The emission in solid is accounted for in the effective thermal conductivity expression of the optically semi-transparent material of packed bed and the emission from the glass cover is negligible.

(v) The boundary surface and the packed bed are gray materials [15] and the optical properties are independent of the wavelength.

Under these conditions, the relation between radiosity (R) and irradiation (I) can be obtained by equating the amount of energy leaving the surface of the glass cover to the sum of the amount of energy reflected by glass cover and the amount of energy transmitted by glass cover. This can be written as

$R=r_{c} I+\left(1-\alpha_{c}-r_{c}\right) I_{1}$

where, $r_{c}$ is the reflectivity of glass cover and $\alpha_{c}$ is the absorptivity of glass cover.

Similarly it can be shown that

$R_{1}=\left(1-\alpha_{c}-r_{c}\right) I+r_{c} I_{1}$

$I_{1}=R_{2} \exp \left(-\tau_{0}\right)$

$I_{2}=R_{1} \exp \left(-\tau_{0}\right)$

$R_{2}=\left(1-\varepsilon_{w}\right) I_{2}$

$I_{y}=R_{1} \exp (-\tau)$

$R_{y}=R_{2} \exp \left[-\left(\tau_{0}-\tau\right)\right]$

where, $\tau$ is the optical depth and can be defined as a measure of the ability of a given path length of the gas to attenuate radiation of a given wavelength and depends directly on the extinction coefficient $(\beta)$ and the thickness $(D)$ of absorbing-scattering layer and expressed as: $\tau=\beta y ; 0 \leq y \leq D$

The optical depth at $\mathrm{y}=0$ and $\mathrm{y}=\mathrm{D}$ then given as:

at $\quad y=0 ; \tau=0$

and at $y=D ; \tau_{0}=\beta D$

Then radiative flux, $Q_{r}$, represented by the difference of irradiance and radiosity, can be written as:

$\mathrm{Q}_{\mathrm{r}}=\mathrm{R}_{1} \exp (-\tau)-\mathrm{R}_{2} \exp \left[-\left(\tau_{0}-\tau\right)\right]$

Eq. (8) can be written in terms of non-dimensional parameters as:

$\mathrm{Q}_{\mathrm{r}}^{*}=\mathrm{R}_{1}^{*} \exp (-\tau)-\mathrm{R}_{2}^{*} \exp \left[-\left(\tau_{0}-\tau\right)\right]$

where, $\mathrm{R}_{1}^{*}=\frac{\mathrm{R}_{1}}{\mathrm{k}_{\mathrm{e}} \beta \mathrm{T}_{\mathrm{i}}} ; \mathrm{R}_{2}^{*}=\frac{\mathrm{R}_{2}}{\mathrm{k}_{\mathrm{e}} \beta \mathrm{T}_{\mathrm{i}}} ; \mathrm{Q}_{\mathrm{r}}^{*}=\frac{\mathrm{Q}_{\mathrm{r}}}{\mathrm{k}_{\mathrm{e}} \beta \mathrm{T}_{\mathrm{i}}}$

Here, $k_{e}$ is the effective thermal conductivity of packing material $\left(\mathrm{Wm}^{-1} \mathrm{~K}^{-1}\right), T_{i}$ is the inlet temperature of air $(\mathrm{K})$.

\subsubsection{Convection}

Convection heat transfer between the air and packed bed matrix is most significant mode of heat transfer in a packed bed type solar air heater under the low temperature operating condition.

For the system shown in Figure 1, the convective heat transfer occurs between the following

(i) Glass cover and the environment air.

(ii) Air flowing in the upper side of the collector and glass cover.

(iii) Solid - fluid - solid.

(iv) Lateral mixing of fluid, and

(v) Front surface of the absorber plate and the air flowing above it.

Items (i) and (ii) are accounted for in the overall loss coefficient.

The mathematical equation for calculating the value of convective heat transfer coefficient, $h_{c}$, is expressed as [4]

$N u=\left(0.5 \operatorname{Re}^{1 / 2}+0.2 \operatorname{Re}^{2 / 3}\right) \operatorname{Pr}^{1 / 3}$

where, Reynolds number $(\mathrm{Re})$ and Nusselt number $(\mathrm{Nu})$ are as follows:

$$
\begin{aligned}
& \operatorname{Re}=u^{0} L^{0} / v=\rho Q D_{p} / \mu A(1-p)=\frac{D_{p} G}{\mu(1-p)} \\
& N u=h_{c} L^{0} / k_{g}=\frac{h_{c} D_{p}}{k_{g}}\left(\frac{p}{1-p}\right)
\end{aligned}
$$

where, $D_{p}$ is the diameter of glass beads.

The relationship between the surface heat transfer coefficient, $h_{c}$, and volumetric heat transfer coefficient, $h_{v}$, is expressed as:

$h_{v}=h_{c} A_{v}$

where surface area per unit volume $\left(\mathrm{m}^{2} \mathrm{~m}^{-3}\right)$ :

$A_{v}=\frac{A_{p}}{V_{p}}(1-p)$

Here $A_{p}$ and $V_{p}$ are the surface area and volume of packing materials. 


\subsubsection{Conduction}

Heat transfer by conduction in the direction of fluid flow is negligible [3] as compared to that in the transverse direction i.e. the direction perpendicular to the air flow. Heat transfer by conduction has been hypothesized to take place through the contact surface of two packings/particles and through solids. Since, due to complexities of matrix geometry and heat flow patterns involved, it is difficult to use the normal thermal conductivity of the bed material; an effective thermal conductivity is employed for such type of system which takes care of the effect of radiation exchange between solids and between neighboring voids, the thermal conductivity of solid and air, the bed voidage and temperature of the bed material and the air.

The following expression for effective thermal conductivity, $k_{e}$, has been developed [32]:

$k_{e}=k_{e}^{0}+\left(k_{e}\right)_{t}$

where, $\left(\mathrm{k}_{\mathrm{e}}\right)_{\mathrm{t}}=\left(\begin{array}{ll}\dot{\alpha} & \beta\end{array}\right) D_{p} \mathrm{c}_{p} G$

The value of $(\dot{\alpha} \beta)$ lie in a narrow range from 0.1 to 0.14 for different packing conditions, an intermediate value of 0.12 has been used in this work. $\mathrm{k}_{\mathrm{e}}^{0}$ is the stagnant bed thermal conductivity which is a function of the fluid and solid phase thermal conductivities, as well as the bed geometry and has been expressed as [15,32].

$$
\begin{aligned}
& k_{e}^{0}=\frac{1+p^{1.3}}{k_{s}+\left(\frac{h_{r v} p^{1.3}}{\left(1-p^{1.3}\right)}\right)+\frac{1}{\left[\left(\frac{k_{g}}{\varphi}\right)+h_{r s} D_{p}\right]}} \\
& +\frac{4 h_{r v} p^{1.3} D_{p} k_{s}}{k_{s}+\left(\frac{h_{r v} D_{p} p^{1.3}}{\left(1-p^{1.3}\right)}\right)+\left(\frac{k_{g}}{\varphi}\right)+h_{r s} D_{p}}+\frac{16 n \sigma T_{b}^{3}}{3 \beta}
\end{aligned}
$$

where, $h_{r v}$ and $h_{r s}$ are radiative heat transfer coefficient from void to void and solid surface to solid surface respectively and are given by

$h_{r v}=\left[\frac{0.1952}{\left\{1+\frac{p}{2(1-p)}\left(\frac{1-\varepsilon}{\varepsilon}\right)\right\}}\right] \times\left(\frac{T_{b}}{100}\right)^{3}$

$h_{r s}=0.1952\left[\left\{\frac{\varepsilon}{(2-\varepsilon)}\right\} \times\left(\frac{T_{b}}{100}\right)^{3}\right]$

and $\varepsilon$ is the emissivity of solid surface, $k_{s}$ and $k g$ are the thermal conductivities of bed material and air respectively $\left(\mathrm{Wm}^{-1} \mathrm{~K}^{-1}\right), T_{b}$ is the temperature of bed $(\mathrm{K}), \varphi$ is the angle factor i.e. the ratio of the effective thickness of fluid film in the void in relation to thermal conduction to diameter of packing material $\left(=l_{v} / \mathrm{D}_{p}\right), l_{v}$ is the effective thickness of fluid film in void $(\mathrm{m}), n$ is the refractive index of packing, $\sigma$ is the Stefan-Boltzmann constant, and $\beta$ is the extinction coefficient of matrix $\left(\mathrm{m}^{-1}\right)$.

\section{Heat Transfer Equations}

Heat transfer equations developed by Hastani et al. [15] in terms of bed and air temperatures respectively by $T_{\mathrm{b}}(x, y)$ and $T_{\mathrm{g}}(x, y)$ have been modified in the present investigation for quasi-steady state conditions as per convention in air heaters. This analysis therefore neglects the effect of storage which appears to be small in comparison with amounts of energy transfer involved.

These modifications have been made to make the analysis suitable for comparison of performance with a conventional air heater and to present the results of performance in a conventional way.

Accordingly, the heat transfer equation developed by Hastani et al. [15] for the system (bed) shown in Figure 1 can be written as

$$
\frac{\partial}{\partial y}\left(k_{e} \frac{\partial T_{b}}{\partial y}-Q_{r}\right)=h_{c} A_{v}\left(T_{P}-T_{g}\right)
$$

where $T_{p}$ is the temperature of packed material (K), and $T_{g}$ is the temperature of air (K). Using the relationship between volumetric and area heat transfer coefficient $\left(h_{v}=A_{v} h_{c}\right)$ the above equation can be modified to:

$\frac{\partial}{\partial y}\left(k_{e} \frac{\partial T_{b}}{\partial y}-Q_{r}\right)=h_{v}\left(T_{p}-T_{g}\right)$

The boundary conditions for the system can be written as:

At, $y=0$;

$k_{e} \frac{\partial T_{b}}{\partial y}-h_{w}\left(T_{p}-T_{c}\right)=0$

where, $h_{w}$ is the wall heat transfer coefficient for the glass cover.

Furthermore, Hastani's analysis did not consider the effect of wind convection and sky radiations because experiments were performed indoor [15]. Therefore the boundary condition at top surface of the collector (i.e. at $\mathrm{y}=0$ ) has been modified to include the above effects by introducing the overall loss coefficients, $\mathrm{U}_{\mathrm{L}}$, as is conventionally considered for outdoor conditions.

Writing heat loss term, $\left(h_{w}=T_{p}-T_{c}\right)$ in terms of overall loss coefficient, $\mathrm{U}_{\mathrm{L}}$, Eq. (22) can be modified to:

At, $\mathrm{y}=0$;

$k_{e} \frac{\partial T_{b}}{\partial y}-U_{L}\left(T_{b}-T_{a}\right)=0$

where, $T_{b}$ is the temperature of packed-bed and can be approximated by average temperature of the packing and the air as: $T_{b}=\left(T_{p}+T_{g}\right) / 2$ and $T_{a}$ is the temperature of surrounding.

At, $y=D$;

$k_{e} \frac{\partial T_{b}}{\partial y}-Q_{r}=0$

For the air flow, the energy equation can be written as: 
$c_{p} \rho \bar{u} \frac{\partial T_{g}}{\partial x}=-h_{c} A_{v}\left(T_{g}-T_{p}\right)$

where, $\rho$ is the density of air $\left(\mathrm{kgm}_{-3}\right), \bar{u}$ is the average velocity of air in duct $\left(\mathrm{ms}^{-1}\right)$.Using volumetric heat transfer coefficient, $h_{v}$, the Eq. (25) becomes

$G c p \frac{\partial T_{g}}{\partial x}=h_{v}\left(T_{p}-T_{g}\right)$

At $x=0$,

$\mathrm{T}_{\mathrm{g}}=\mathrm{T}_{\mathrm{i}}$

The following non-dimensional parameters are introduced in order to normalize the above equations:

$\tau=\beta y, \mathrm{~T}_{\mathrm{b}}^{*}=\frac{\mathrm{T}_{\mathrm{b}}}{\mathrm{T}_{\mathrm{i}}}, \mathrm{T}_{\mathrm{g}}^{*}=\frac{\mathrm{T}_{\mathrm{g}}}{\mathrm{T}_{\mathrm{i}}}, \mathrm{T}_{\mathrm{a}}^{*}=\frac{\mathrm{T}_{\mathrm{a}}}{\mathrm{T}_{\mathrm{i}}}, \bar{x}=\frac{x}{\mathrm{~L}}, \mathrm{~h}_{\mathrm{v}}^{*}=\frac{2 \mathrm{~h}_{\mathrm{v}} \mathrm{L}}{\mathrm{Gc}_{\mathrm{p}}}$

$\mathrm{h}_{\mathrm{v}}^{* *}=\frac{2 \mathrm{~h}_{\mathrm{v}}}{\mathrm{k}_{\mathrm{e}} \beta^{2}}, \mathrm{Q}_{\mathrm{r}}^{*}=\frac{\mathrm{Q}_{\mathrm{r}}}{\mathrm{k}_{\mathrm{e}} \mathrm{T}_{\mathrm{i}} \beta}, \mathrm{U}_{\mathrm{L}}^{*}=\frac{\mathrm{U}_{\mathrm{L}}}{\mathrm{k}_{\mathrm{e}} \beta}$

Eqs. (21) to (27) can be rewritten as follows:

\section{For Packing Material}

$\frac{\partial^{2} T_{b}^{*}}{\partial \tau^{2}}-\frac{\partial}{\partial \tau}\left(Q_{r}^{*}\right)=h_{v}^{* *}\left(T_{b}^{*}-T_{g}^{*}\right)$

Introducing the value of $Q_{r}^{*}$ from Eq. (9), the above equation can be rewritten as:

$\frac{\partial^{2} T_{b}^{*}}{\partial \tau^{2}}-\frac{\partial}{\partial \tau}\left[R_{1}^{*} \exp (-\tau)-R_{2}^{*} \exp -\left(\tau_{0}-\tau\right)\right]=h_{v}^{* *}\left(T_{b}^{*}-T_{g}^{*}\right)$

which further simplified as:

$\frac{\partial^{2} T_{b}^{*}}{\partial \tau^{2}}+R_{1}^{*} \exp (-\tau)+R_{2}^{*} \exp \left[-\left(\tau_{0}-\tau\right)\right]=h_{v}^{* *}\left(T_{b}^{*}-T_{g}^{*}\right)$

with following boundary conditions:

$$
\text { At } \tau=0
$$

$\frac{\partial T_{b}^{*}}{\partial \tau}-U_{L}^{*}\left(T_{b}^{*}-T_{a}^{*}\right)=0$

$$
\text { At } \tau=\tau_{0}
$$

$\frac{\partial T_{b}^{*}}{\partial \tau}-Q_{r}^{*}=0$

\section{For Air}

$\frac{\partial T_{g}^{*}}{\partial \bar{x}}=h_{v}^{*}\left(T_{b}^{*}-T_{g}^{*}\right)$

with following boundary condition:

$$
\text { At } \bar{x}=0
$$

$\mathrm{T}_{\mathrm{g}}^{*}=1$

\section{Numerical Solution of the Differential Equations}

Equations (29) and (32) are two dimensional, linear coupled partial differential equations. An exact analytical solution of this system of equations is not possible [8], however exact solution can be approximated to any desired degree of accuracy by numerical methods. These differential equations have been transformed into finite difference equations using central, forward and backward difference formulae. They are deduced from general Newtonian formula by a suitable choice of the sequence of the fundamental points. The finite difference equations have been written for various nodes and the simultaneous equations so obtained, have been solved. The technique of transforming the differential equations into finite difference equations is discussed below:

Considering two-dimensional region covered with rectangular mesh as shown in Figure 2. The mesh consists of $\mathrm{N}$ vertical and $\mathrm{M}$ horizontal lines positioned at intervals of length $\Delta \bar{x}$ and $\Delta \tau$, respectively.

For convenience non-dimensional bed temperature $\mathrm{T}_{\mathrm{b}}^{*}$ has been designated by $\mathrm{u}$ and non-dimensional air temperature $\mathrm{T}_{\mathrm{g}}^{*}$ by $\mathrm{v}$ and writing the Eq. (29) in difference form using central difference formula as:

$$
\begin{aligned}
& \frac{u_{i, j+1}-2 u_{i, j}+u_{i, j-1}}{(\Delta \tau)^{2}}+R_{1}^{*} e^{-(j \Delta \tau)}+R_{2}^{*} e^{-\left(\tau_{0}-j, \Delta \tau\right)} \\
& =h_{v}^{* *}\left(u_{i, j}-v_{i, j}\right)
\end{aligned}
$$

or,

$u_{i, j+1}-2 u_{i, j}+u_{i, j-1}+\Delta \tau^{2}\left(R_{1}^{*} e^{-j \Delta \tau}+R_{2}^{*} e^{-\left(\tau_{0}-j \Delta \tau\right)}\right)$

$=h_{v}^{* *} \Delta \tau^{2}\left(u_{i, j}-v_{i, j}\right)$

$u_{i, j}=\frac{1}{\left(2+h_{v}^{* *} \Delta \tau^{2}\right)}\left(u_{i, j+1}+u_{i, j-1}+h_{v}^{* *} \Delta \tau^{2} v_{i, j}\right.$

$\left.+\Delta \tau^{2}\left(R_{1}^{*} e^{-j \Delta \tau}-R_{2}^{*} e^{-\left(\tau_{0}-j \Delta \tau\right)}\right)\right)$

with $0 \leq \mathrm{i} \leq \mathrm{N}, 1 \leq \mathrm{j} \leq \mathrm{M}-1$

The above equation can be used for writing the difference equations for packed bed temperature at various nodes except at $\mathrm{j}=0$ and $\mathrm{j}=\mathrm{M}$ because at $\mathrm{j}=0$, the term $\mathrm{u}_{\mathrm{i},-1}$ and $\mathrm{j}=\mathrm{M}$, the term $\mathrm{u}_{\mathrm{i}, \mathrm{M}+1}$ are out of boundary. For writing the equations of bed temperature at the boundaries (i.e. at $\mathrm{j}=0$ and $\mathrm{j}=\mathrm{M}$ ), the boundary conditions Eqs. (30) and (31) have to be used.

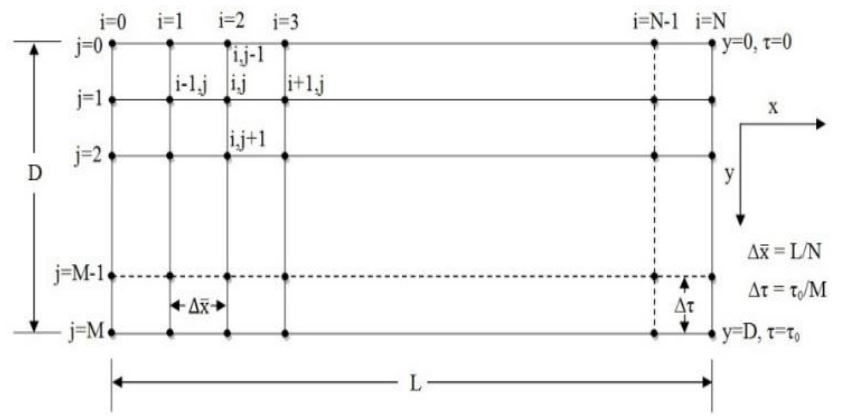

Figure 2. The discretization of a two dimensional domain.

Writing the Eq. (30) in difference form using forward difference formula as:

$$
\frac{u_{i, j+1}-u_{i, j}}{\Delta \tau}-U_{L}^{*}\left(u_{i, j}-T_{a}^{*}\right)=0 ; \text { at } \mathrm{j}=0
$$

or, 
$u_{i, j}=\left(\frac{1}{1+\Delta \tau U_{L}^{*}}\right)\left(u_{i, j+1}+\Delta \tau U_{L}^{*} T_{a}^{*}\right) ;$ at $\mathrm{j}=0$

therefore,

$u_{i, 0}=\left(\frac{1}{1+\Delta \tau U_{L}^{*}}\right)\left(u_{i, 1}+\Delta \tau U_{L}^{*} T_{a}^{*}\right) ;$ at $0 \leq i \leq N$

The above equation can be used for writing the equations of bed temperature on top boundary (i.e. at $y=0$ ) at different nodes. Writing the equation (31) in difference form using backward difference formulae as:

$\frac{u_{i, j}-u_{i, j-1}}{\Delta \tau}-Q_{r}^{*}=0 ; a t j=M$

$u_{i, j}=u_{i, j-1}+\Delta \tau Q_{r}^{*} ; a t j=M$

or, $u_{i, M}=u_{i, M-1}+\Delta \tau Q_{r_{3}}^{*} ; 0 \leq i \leq N$

where

$\mathrm{Q}_{\mathrm{r}}^{*}=\frac{I_{2}-R_{2}}{\mathrm{k}_{\mathrm{e}} \beta \mathrm{T}_{\mathrm{i}}}$

The above equation can be used for writing the bed temperature equations at different nodes on bottom boundary (i.e. at $y=D$ ). Writing the differential Eq. (32) in difference form using backward difference formula as:

$\frac{v_{i, j}-v_{i-1, j}}{\Delta \bar{x}}=h_{v}^{*}\left(u_{i, j}-v_{i, j}\right)$

or,

$v_{i, j}=\left(\frac{1}{1+\Delta \bar{x} h_{v}^{*}}\right)\left(v_{i-1, j}+\Delta \bar{x} h_{v}^{*} u_{i, j}\right) ;$

with $0 \leq \mathrm{i} \leq \mathrm{N}, 0 \leq \mathrm{j} \leq \mathrm{M}$.

Using the above difference equation, the equations for air temperature at different nodes can be written except at $\mathrm{i}=0$. From Eq. (33),

at $\mathrm{x}=0$;

$\mathrm{T}_{\mathrm{g}}^{*}=1$

i.e. at $\mathrm{i}=0 ; \mathrm{v}_{\mathrm{i}, \mathrm{j}}=1$

or,

$\mathrm{v}_{0, \mathrm{j}}=1 ; 0 \leq \mathrm{j} \leq \mathrm{M}$

Using finite difference equations (Eqs. 36 to 40), the equation for temperature of bed and air at different nodes have been written with $2(\mathrm{M}+1)(\mathrm{N}+1)$ number of equations and equal number of unknowns. These simultaneous equations have been written in matrix form to obtain numerical solution by writing the computer programme in $\mathrm{C}++$ programming language (see flow chart Figure 3 ).

\section{Thermal and Thermo-hydraulic Performance}

The obtained outlet air temperatures for given operating conditions are used to calculate the thermal efficiency $\left(\eta_{t h}\right)$ using the following relations:

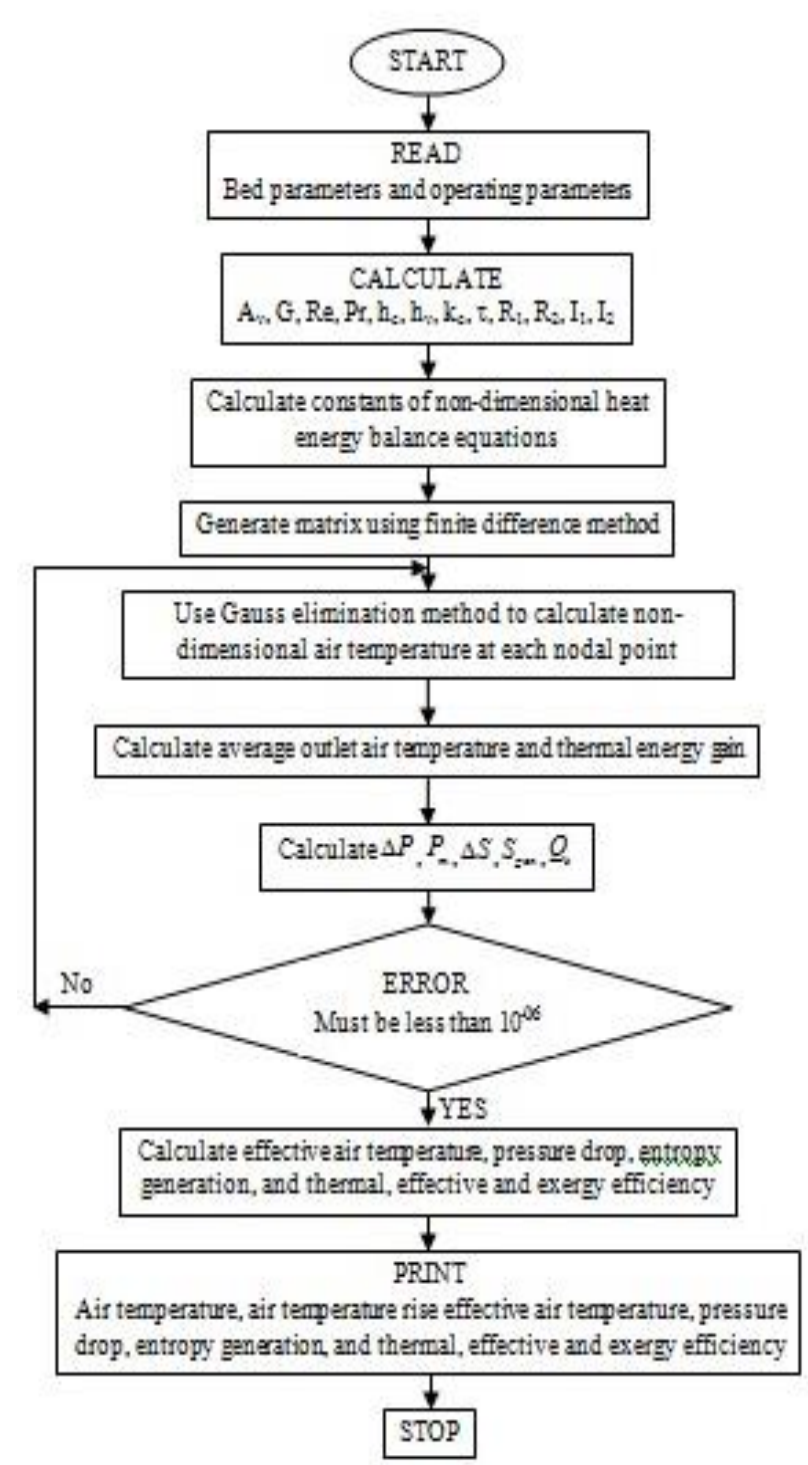

Figure 3. Flow chart for iterative solution of mathematical model.

$\eta_{t h}=\frac{Q_{u}}{I A_{c}}$

where, $\mathrm{Q}_{\mathrm{u}}$ is the useful heat gain of the collector can be written as

$Q_{u}=m c p(\Delta \mathrm{T})$

and $\Delta \mathrm{T}=\left(\mathrm{T}_{o}-\mathrm{T}_{i}\right)$; is the air temperature rise. The net energy gain, $Q_{e}$ of the collector can be expressed as the difference between the useful thermal energy gain, $Q_{u}$, and the equivalent thermal energy required for producing the work energy necessary to overcome the pressure energy losses. This net energy can be written as:

$Q_{e}=Q_{u}-P_{m} / C_{f}$

where, $P_{m}$ is the work energy lost in friction in the heater channel, given by:

$P_{m}=m \Delta P / C_{f}$

$C_{f}$ is the conversion factor to transform different efficiencies (thermal to mechanical) and is taken 0.2 and $\Delta P$ is the pressure drop, calculated as: 


$$
\Delta P=\frac{L}{g_{c}} 1.75\left[\frac{(1-p)}{p^{3}} \frac{G V}{D_{p}}\right]+150 \frac{(1-p)^{2}}{p^{3}} \frac{\mu V}{D_{p}^{2}}
$$

$\mathrm{V}$ is the superficial mean gas velocity $(G / \rho) \mathrm{ms}^{-1}$.

The thermohydraulic performance parameter (effective efficiency) can now be written using equations (42)-(44) as:

$\eta_{e f f}=m c_{p}\left[\left(T_{o}-T_{i}\right)-C_{m}\right] / I A_{c}$

where, $C_{m}$ is the equivalent temperature drop due to friction and is given by:

$$
C_{m}=\Delta P /\left(C_{f} \rho c_{p}\right)
$$

The effective temperature rise is given as:

$$
\Delta T_{e}=\left[\left(T_{o}-T_{i}\right)-C_{m}\right]
$$

\section{Exergy Analysis}

This article focuses on the combination of the two laws of thermodynamics, which are described in the concept of exergy analysis.

The assumptions made in the analysis presented in this study are:

(i) steady state, steady flow operation

(ii) negligible potential and kinetic energy effects and no chemical or nuclear reactions

(iii) air is an ideal gas with a constant specific heat, and its humidity content is ignored

(iv) the directions of heat transfer to the system and work transfer from the system are positive. form as

The mass balance equation can be expressed in the rate

$$
\Sigma m_{\text {in }}=\Sigma m_{\text {out }}
$$

Where, $m$ is the mass flow rate, and the subscript in stands for inlet and out for outlet.

If the effects due to the kinetic and potential energy changes are neglected, the general energy and exergy balances can be expressed in rate form as given below [33]:

$$
\begin{aligned}
& \Sigma E_{\text {in }}=\Sigma E_{\text {out }} \\
& \Sigma E x_{\text {in }}-\Sigma E x_{\text {out }}=\Sigma E x_{\text {dest }}
\end{aligned}
$$

or

$$
E x_{\text {heat }}-\mathrm{E} x_{\text {work }}+\mathrm{E} x_{\text {mass, in }}-\mathrm{E} x_{\text {mass,out }}=\mathrm{E} x_{\text {dest }}
$$

Using the Eq. (52) the rate form of the general exergy balance can be expressed as follows:

$$
\Sigma\left(1-\frac{T_{a}}{T_{s}}\right) \mathrm{Q}_{s}-\mathrm{W}+\Sigma m_{\text {in }} \psi_{i}-\Sigma m_{\text {out }} \psi_{o}=\mathrm{E} x_{\text {dest }}
$$

where,

$$
\begin{aligned}
& \psi_{i}=\left(h_{i}-h_{a}\right)-T_{a}\left(s_{i}-s_{a}\right) \\
& \psi_{o}=\left(h_{o}-h_{a}\right)-T_{a}\left(s_{o}-s_{a}\right)
\end{aligned}
$$

If Eqs. (54) and (55), are substituted in Eq. (53), it is arranged as below:
$\left(1-\frac{T_{a}}{T_{s}}\right) \mathrm{Q}_{s}-m\left[\left(h_{o}-h_{i}\right)-T_{a}\left(s_{o}-s_{i}\right)\right]=\mathrm{E} x_{d e s t}$

where Qs is the solar energy absorbed by the collector absorber surface and it is evaluated with the expression given below:

$Q_{s}=I\left(\tau_{c} \alpha\right) A_{C}$

The changes in the enthalpy and the entropy of the air at the collector are expressed by

$$
\begin{aligned}
& \Delta h=h_{o}-h_{i}=c_{p}\left(T_{o}-T_{i}\right) \\
& \Delta s=s_{o}-s_{i}=c_{p} \ln \frac{T_{o}}{T_{i}}-\dot{R} \ln \frac{P_{o}}{P_{i}}
\end{aligned}
$$

By substituting Eqs. (57) - (59), into Eq. (56) the equation below can be derived:

$$
\begin{aligned}
& \left(1-\frac{T_{a}}{T_{s}}\right) I\left(\tau_{c} \alpha\right) A_{C}-m c_{p}\left(T_{o}-T_{i}\right)+m c_{p} T_{a} \ln \frac{T_{o}}{T_{i}} \\
& -m \dot{R} T_{a} \ln \frac{P_{o}}{P_{i}}=\mathrm{E} x_{d e s t}
\end{aligned}
$$

The exergy destruction or the irreversibility may be expressed as follows:

$E x_{\text {dest }}=T_{a} S_{\text {gen }}$

The exergetic efficiency is calculated as follows:

$\eta_{I I}=1-\frac{T_{a} S_{g e n}}{\left[1-\left(T_{a} / T_{s}\right)\right] Q_{s}}$

where, $T_{s}$ is the temperature of sun and assumed as 5600 $\mathrm{K}$.

\section{Results and Discussion}

The air temperature rise and other performance parameters are obtained analytically by varying the system and operating parameters like diameter of spherical glass beads matrix, channel/duct depth, mass flow rate of air.

The values of extinction coefficient, porosity and surface area/volume of glass bead matrices were taken from Collier [14] and Hastani [15] corresponding to diameter of glass beads are listed in Table 1 . The reflectivity $\left(r_{c}\right)$ and absorptivity $\left(\alpha_{c}\right)$ of glass cover for normal incidence have been taken as 0.0434 and 0.1296 respectively; which were determined using the expressions available in Duffie and Beckmann [34] and using the refractive index of 1.5 and extinction coefficient of glass cover as 34.0 per meter [34]. The angle factor $(\varphi)$ corresponding to porosity of the bed was obtained from the graphical form of relationship as proposed by Kunii and Smith [35]. An average value of 0.12 was found for the range of porosity employed. The thermo-physical properties of air at average temperature were used for calculation of volumetric heat transfer coefficient, $h_{v}$. The values of system and operating parameters used for evaluation of air temperature rise, thermal efficiency, thermo-hydraulic efficiency and exergetic efficiency are given in Table 2. 
Table 2: Numerical values of system and operating parameters used in analytical investigation of glass beads packed bed solar air heater.

\begin{tabular}{|cll|}
\hline S. No. & Input data & Numerical value \\
1. & Length of collector, $(L)$ & $1.25 \mathrm{~m}$ \\
2. & Width of collector, $(W)$ & $0.8 \mathrm{~m}$ \\
3. & Collector area, $\left(A_{c}\right)$ & $1 \mathrm{~m}^{2}$ \\
4. & Depth of collector, $(D)$ & $0.02,0.04,0.06,0.08,0.10 \mathrm{~m}$ \\
5. & Mass flow rate of air, $(m)$ & $0.005,0.01,0.02,0.03,0.04,0.05$ and $0.06 \mathrm{kgs}^{-1}$ \\
6. & Inlet temperature, $\left(T_{i}\right)$ & $30^{\circ} \mathrm{C}$ \\
7. & Ambient temperature, $\left(T_{a}\right)$ & $30^{\circ} \mathrm{C}$ \\
8. & Insolation, $(I)$ & $950 \mathrm{Wm}^{-2}$ \\
9. & Absorptivity of glass beads, $(\alpha)$ & 0.25 \\
10. & Emissivity of bottom plate, $\left(\varepsilon_{w}\right)$ & 0.8 \\
11. & Thermal conductivity of glass beads matrices, $\left(k_{s}\right)$ & $0.743 \mathrm{Wm}^{-1} \mathrm{~K}^{-1}$ \\
12. & Overall loss coefficient, $\left(U_{L}\right)$ & $7 \mathrm{Wm}^{-2}{ }^{\circ} \mathrm{C}$ \\
13. & Reflective index of glass beads material, $(n)$ & 1.5 \\
\hline
\end{tabular}

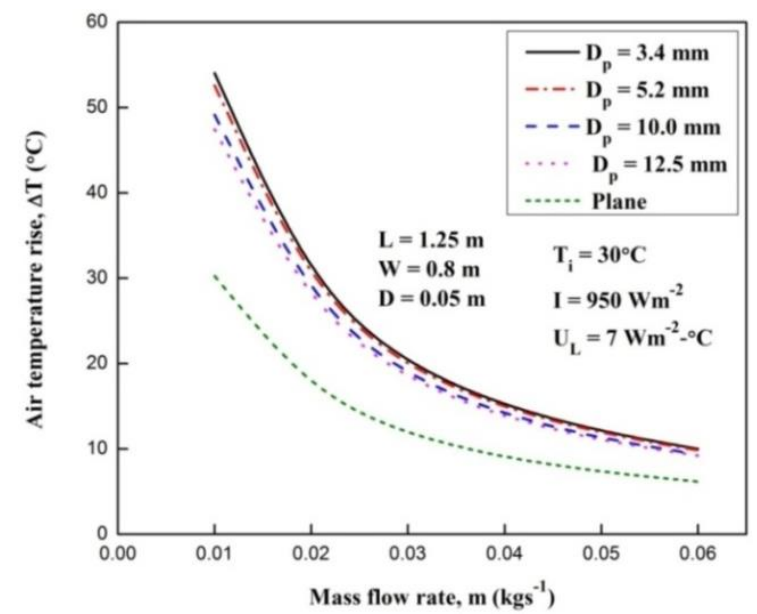

Figure 4. Air temperature rise as a function of mass flow rate for different diameter of glass beads.

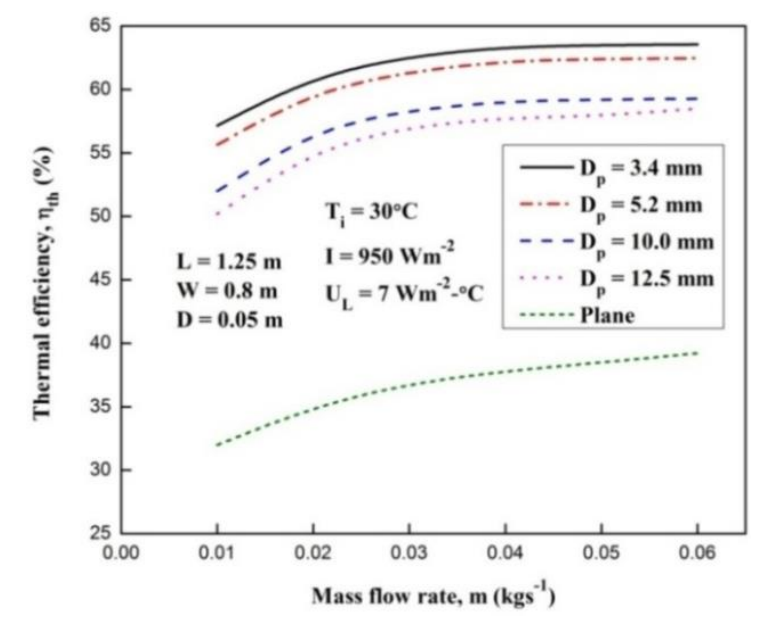

Figure 5. Thermal efficiency as a function of mass flow rate for different diameter of glass beads

Figure 4 and 5 show the air temperature rise and thermal efficiency as a function of mass flow rate of packed bed solar air heaters for different diameter of glass beads. As obvious, the value of air temperature rise $\Delta T$ is seen to fall with increasing mass flow rate for all values of glass beads diameter. The temperature fall for fixed solar radiation intensity although monotonic but is seen to be non-linear, the higher mass flow rates showing less steeper fall because of relatively higher rate of energy collection as a result of higher heat transfer rates and relatively lesser thermal losses whereas, the thermal efficiency monotonically increases with an increase in mass flow rates apparently because of an increase in the convective heat transfer coefficient; the bed packed with smaller diameter of glass beads $(3.4 \mathrm{~mm})$ maintains the highest efficiency value throughout the range of mass flow rate investigated. Furthermore, a slight fall is observed in the rate of increase of efficiency as mass flow rate increases, apparently due to relatively lower percentage increase in surface conductance as mass flow rate increases as also due to increase in convective heat transfer coefficient between bed and the glass plate and higher thermal losses.

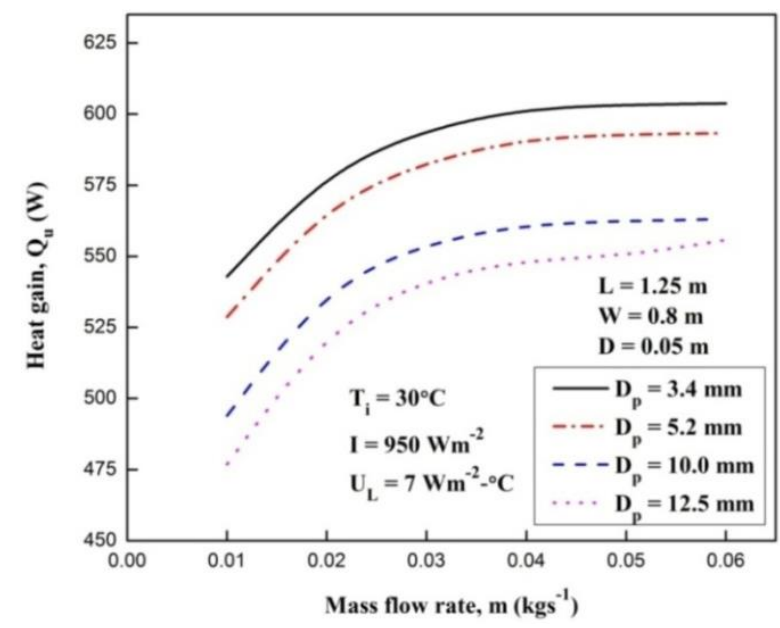

Figure 6. Heat gain as a function of mass flow rate for different diameter of glass beads. 
Figure 6 illustrates the variation of the heat gain, $Q_{u}$, with mass flow rate for different diameter of glass beads. It is seen from the figure that as the mass flow rate increases heat gain increases due to enhance rate of heat transfer for all values of particle diameter. The bed with smaller particle diameter $(3.4 \mathrm{~mm})$ delivers more energy as compared to others. This is due to increased rate of heat transfer to the flowing air.

Figure 7 shows the effect of total depth of channel (duct) on efficiency of packed bed collector with a bed of $10 \mathrm{~mm}$ glass beads diameter particle. The corresponding results of plane collector with different total bed depths of duct have also been shown in this figure. The efficiency of plane collector have found to decrease with increase in total bed depth due to decrease in the values of convective heat transfer coefficient between absorber plate and air leading to higher plate temperatures and greater thermal losses. This result is similar to that obtained by previous investigators. However in case of packed bed collectors, the efficiency increases up to a certain total bed depth $(50 \mathrm{~mm})$ and there after found to fall rapidly. The increases in the values of efficiency can be attributed to the fact that any decline in the values of convective heat transfer coefficient as a result of decrease in superficial mass velocity of air is affectively compensated by corresponding increase in heat transfer surface area of packing materials.

It has also been observed that there exists an upper limiting value to total bed depth for packed bed collector beyond which thermal performance begins to fall again and it is seen that this type of characteristics behavior in performance observed at all mass flow rate. A larger total bed depth beyond $50 \mathrm{~mm}$, it appears, fails to adequately compensate for decrease in convective heat transfer coefficient by adding heat transfer surface area because lower volume of bed material is less effective for heat transfer in this region.

Table 3 shows the thermal efficiency for packed bed and plane collector at lower and higher mass flow rate of $0.01 \mathrm{~kg} / \mathrm{s}$ and $0.06 \mathrm{~kg} / \mathrm{s}$ having total bed depth of $50 \mathrm{~mm}$. Inspection of this table show that there is a substantial enhancement in thermal efficiency with packed bed collector. The efficiency of plane collector increases from $32 \%-39.2 \%$ while that of packed bed collector the corresponding increase is found to be $57.15 \%-63.50 \%$; $55.65 \%-62.4 \% ; 52.0 \%-59.2 \%$; and $50.2 \%-57.9 \%$ for a bed of particle diameter of $3.4,5.2,10.0$ and $12.5 \mathrm{~mm}$ respectively. The corresponding enhancement in thermal efficiency at lower and higher mass flow rate of these beds is found to be $78.6 \%-62.0 \% ; 73.9 \%-59.184 \% ; 62.5 \%-$ $51.02 \%$; and $56.9 \%-47.704 \%$. The effect of bed depth for particle diameter $10 \mathrm{~mm}$ have been studied by increasing the total bed depth from $20 \mathrm{~mm}$ to $100 \mathrm{~mm}$, the maximum thermal efficiency have been found to correspond to a total bed depth of $50 \mathrm{~mm}$ as seen from this table.

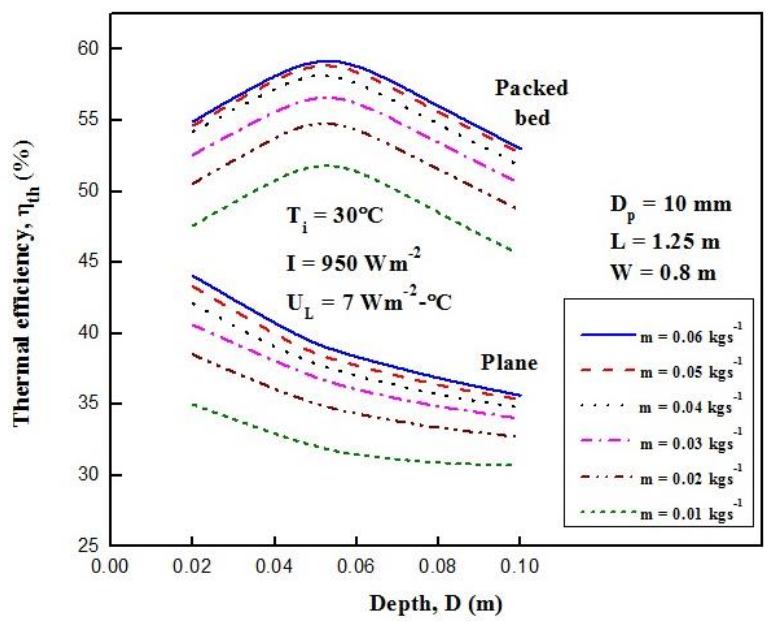

Figure 7. Effect of depth of collector on thermal efficiency.

The effect of mass flow rate of the flowing air on the pressure drop is shown in Figure 8. It is clear that for all diameter of glass beads the pressure drop increases with increasing the mass flow rate due to the increased velocity of the flowing air with increasing mass flow rate;

Table 3. The values of thermal efficiencies for packed-bed and plane collectors at two different mass flow rates.

\begin{tabular}{|c|c|c|c|c|c|c|}
\hline $\begin{array}{c}\text { Figure } \\
\text { No. }\end{array}$ & $\begin{array}{l}\text { Dia. of glass } \\
\text { beads, } \mathbf{D}_{\mathbf{p}} \\
(\mathrm{mm})\end{array}$ & $\begin{array}{l}\text { Total bed } \\
\text { depth, D } \\
(\mathrm{mm})\end{array}$ & $\begin{array}{l}\text { Mass flow } \\
\text { rate, } \mathbf{m} \\
\left(\mathrm{kgs}^{-1}\right)\end{array}$ & $\begin{array}{c}\text { Thermal efficiency } \\
\text { of plane collector } \\
(\%)\end{array}$ & $\begin{array}{c}\text { Thermal } \\
\text { efficiency of } \\
\text { packed bed } \\
(\%)\end{array}$ & $\begin{array}{c}\text { Enhancement of } \\
\text { thermal } \\
\text { efficiency } \\
(\%)\end{array}$ \\
\hline \multirow{2}{*}{ Figure 5} & \multirow{2}{*}{3.4} & \multirow{2}{*}{50} & 0.01 & 32.0 & 57.1 & 78.6 \\
\hline & & & 0.06 & 39.2 & 63.5 & 62.0 \\
\hline \multirow{2}{*}{ Figure 5} & \multirow{2}{*}{5.2} & \multirow{2}{*}{50} & 0.01 & 32.0 & 55.6 & 73.9 \\
\hline & & & 0.06 & 39.2 & 62.4 & 59.2 \\
\hline \multirow{2}{*}{ Figure 5} & \multirow{2}{*}{10.0} & \multirow{2}{*}{50} & 0.01 & 32.0 & 52.0 & 62.5 \\
\hline & & & 0.06 & 39.2 & 59.2 & 51.0 \\
\hline \multirow{2}{*}{ Figure 5} & \multirow{2}{*}{12.5} & \multirow{2}{*}{50} & 0.01 & 32.0 & 50.2 & 56.9 \\
\hline & & & 0.06 & 39.2 & 57.9 & 47.7 \\
\hline \multirow{2}{*}{ Figure 7} & \multirow{2}{*}{10.0} & \multirow{2}{*}{20} & 0.01 & 35.0 & 47.5 & 35.9 \\
\hline & & & 0.06 & 44.0 & 54.9 & 24.6 \\
\hline \multirow{2}{*}{ Figure 7} & \multirow{2}{*}{10.0} & \multirow{2}{*}{40} & 0.01 & 32.9 & 50.9 & 54.7 \\
\hline & & & 0.06 & 40.7 & 58.2 & 43.1 \\
\hline \multirow{2}{*}{ Figure 7} & \multirow{2}{*}{10.0} & \multirow{2}{*}{60} & 0.01 & 31.4 & 51.7 & 64.6 \\
\hline & & & 0.06 & 38.3 & 59.1 & 54.2 \\
\hline \multirow{2}{*}{ Figure 7} & \multirow{2}{*}{10.0} & \multirow{2}{*}{80} & 0.01 & 30.8 & 48.4 & 57.0 \\
\hline & & & 0.06 & 36.8 & 55.9 & 52.1 \\
\hline \multirow{2}{*}{ Figure 7} & \multirow{2}{*}{10.0} & \multirow{2}{*}{100} & 0.01 & 30.7 & 45.5 & 48.3 \\
\hline & & & 0.06 & 35.6 & 53.0 & 48.8 \\
\hline
\end{tabular}




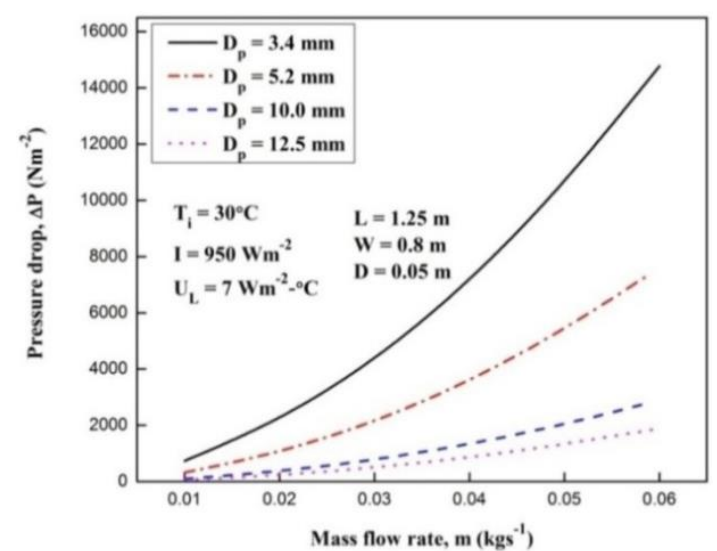

Figure 8. Pressure drop as a function of mass flow rate. consequently, the pressure drop increases (see eq. 5.5). Also pressure drop increases with decrease in diameter of glass beads due to increasing surface resistance of packing materials.

Figure 9 shows the air temperature rise $\Delta T$ and effective air temperature rise $\Delta T_{e}$ as a function of mass flow rate for different diameter of glass beads. It is seen that both $\Delta T$ and $\Delta T_{e}$ decreases with increasing mass flow rate. However, the deviation in the values of $\Delta T$ and $\Delta T_{e}$ are lower at lower mass flow rate and it goes on increasing with increase in mass flow rate. This is because of higher pressure drop at higher air mass flow rate causing loss of energy and consequently decreases the values of air temperature rise.

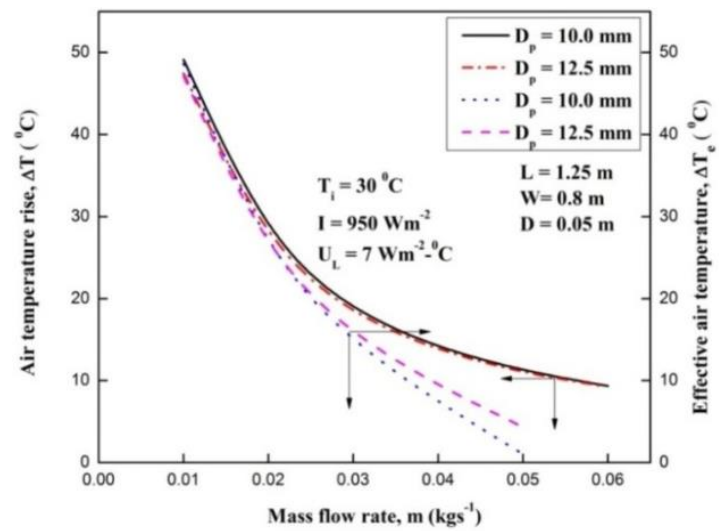

Figure 9. Air temperature rise and effective air temperature as a function of mass flow rate.

The effect of the air mass flow rate on the effective efficiency as well as thermal efficiency is illustrated in Figure 10. It has been found for a bed of three different diameters of glass beads that as the air mass flow rate increases, the effective efficiency increases up to a particular value of mass flow rate, attains maxima, and then decreases sharply. It is noticed that there exists an optimal value of effective efficiency for a given bed of particle, which is due to the fact that the air mass flow rate is a strong parameter that affects the pumping power, there by affecting the effective efficiency. So it is evident that optimum thermo-hydraulic performance is obtained for a particular mass flow rate. It is attributed to the fact that for higher mass flow rates pumping power losses for smaller diameter of glass beads are high as compared to bigger diameter of glass beads matrices due to higher air flow resistance.
It can also be found from the Figure 10 that the thermal efficiency of the solar air heater increases with increasing mass flow rate. This is because the heat removal capacity depends directly on the mass flow rate. In addition, the smaller diameter of glass beads attains higher thermal efficiency due to higher heat transfer area.

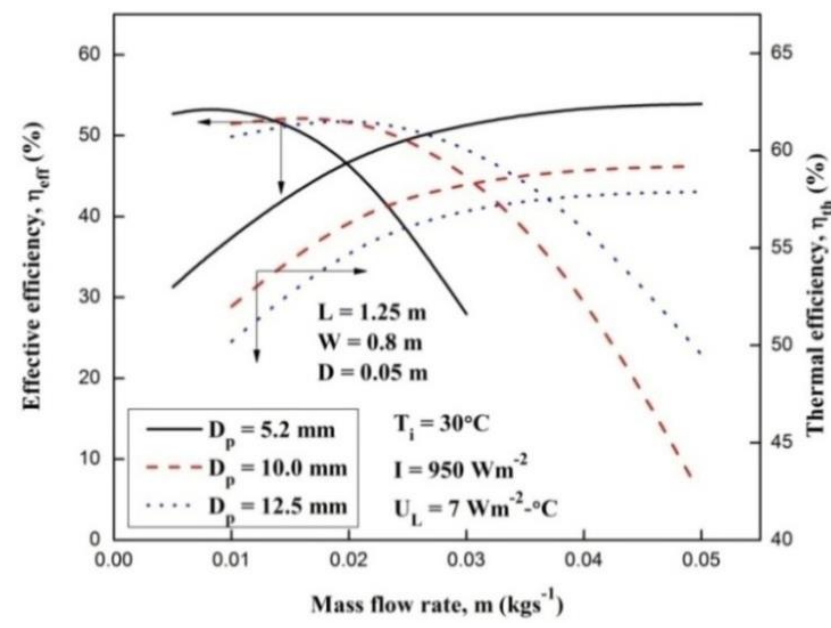

Figure 10. Effective efficiency and thermal efficiency as a function of mass flow rate.

It is seen in Figure 11 that for higher mass flow rates (which corresponds to lower temperature rise parameter), thermal efficiency is higher due to the fact that losses are comparatively low as the air flow is at lower temperature where as for lower mass flow rates, corresponding to higher temperature rise, thermal efficiency is lower as the air temperature is higher. It is also observed that in lower range of temperature rise parameter the effective efficiency decreases sharply, due to the fact that when the temperature rise is found to be low for higher values of mass flow rate i.e. when higher mass flow rate is handled, it increases the frictional losses and due to which more pumping power is required, this reduces the effective efficiency at larger flow rates where as for lower flow rates, rise in temperature shall be higher while the frictional losses would be comparatively lower, resulting in higher effective efficiency.

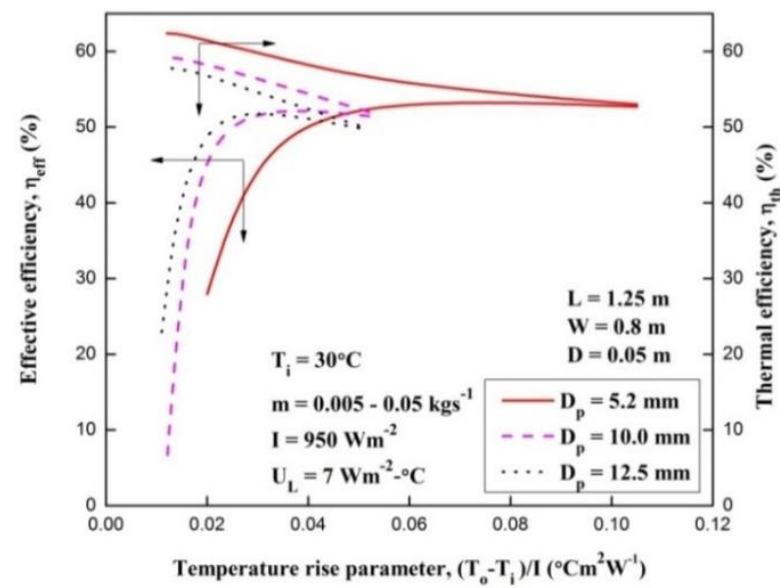

Figure 11. Effective efficiency and thermal efficiency as a function of temperature rise parameter. 


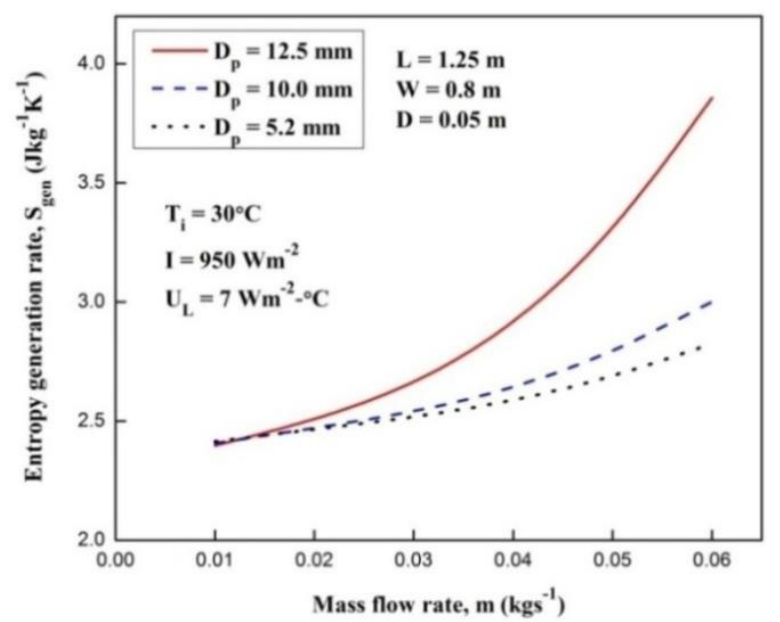

Figure 12. Entropy generation rate as a function of mass flow rate.

Figure 12 shows the variation of the entropy generation rate with air mass flow rate for various diameters of glass beads. It can be seen from figure that the entropy generation rate increases exponentially with increase in mass flow rate of air for all values of glass beads diameter. It can also be seen that the entropy generation rate increases drastically with increase in diameter of glass beads at higher mass flow rate. Figure 13 shows the variation of exergetic efficiency as a function of mass flow rate for packed bed solar air heater for different diameter of glass beads. It can be observed from the figure that, the exergetic efficiency decreases with increase in mass flow rate. This happens due to higher exergy losses. It is also found that the exergetic efficiency becomes negative at higher mass flow rate. The reason is, with increase of mass flow rate of air, the exergy associated with the required pumping power exceeds the exergy of thermal energy collected and thus the net exergy flow and thereby the exergetic efficiency becomes negative.

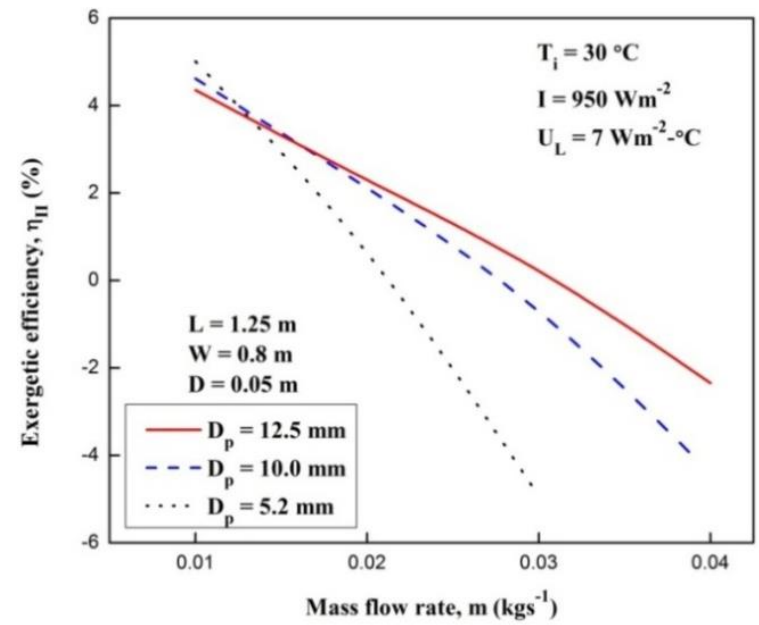

Figure 13. Variation of exergetic efficiency as a function of mass flow rate.

\subsection{Models Validation}

The analytical values of air temperature rise and thermal efficiency of optically semi-transparent material packed bed solar air heaters have been compared with experimental values of Hastani et al. [15] as shown in Figure 14 and 15. For particle diameter of $3.4 \mathrm{~mm}$ the percentage deviation of analytical values of air temperature rise and thermal efficiency and corresponding experimental values have been found to be in the range of 8.87 to -7.89 and 6.98 to 2.125 respectively. This shows the analytical models presented in Article 3 is capable of predicting the performance of optically semitransparent packed bed solar air heaters.

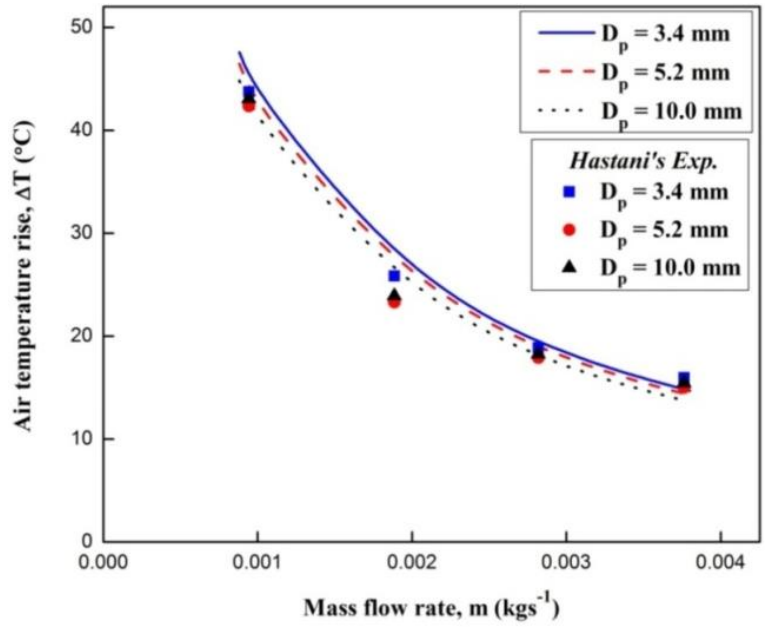

Figure 14. Air temperature rise as a function of mass flow rate for various diameters of glass beads.

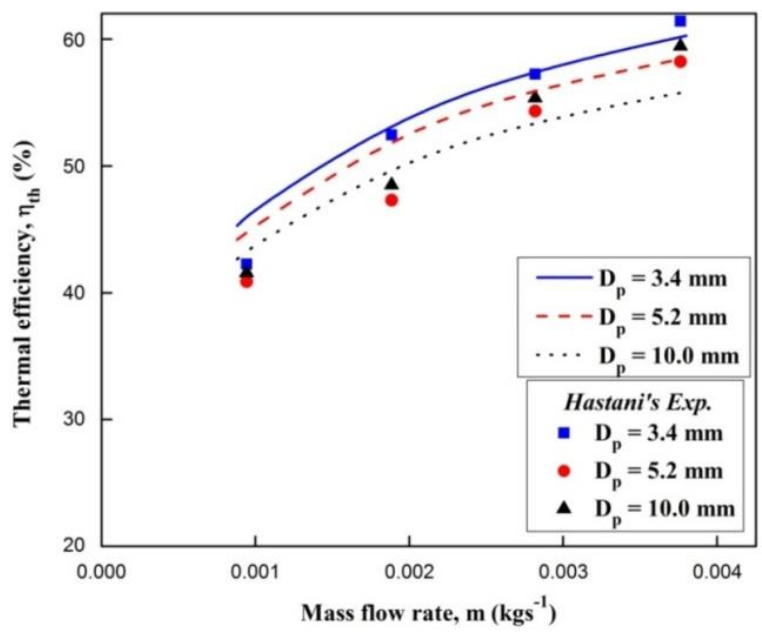

Figure 15. Thermal efficiency as a function of mass flow rate for various diameters of glass beads.

\section{Conclusions}

Based on the results obtained from theoretical models, the following conclusions have been drawn:

(i) The mathematical models based on two dimensional heat and fluid flow in semitransparent materials packed bed solar air heater have been developed to study the effect of system and operating parameters on thermal, thermo-hydraulic and exergy performances.

(ii) A finite difference solution algorithm has been developed for obtaining the numerical solutions of the governing equations for the energy transfer. The detail results of air temperature rise, thermal efficiency, effective efficiency and exergetic efficiency have been obtained.

(iii) A computer program is developed in $\mathrm{C}^{++}$language to estimate the temperature rise of the entering air for evaluation of performance by solving the governing equations numerically using relevant correlations for heat transfer coefficient for optically semi-transparent packed bed systems. 
(iv) A comparison between the air temperature rise and thermal efficiency have been made with the available results and found to be in fairly close agreement.

(v) It has been found that there is a considerable enhancement in thermal efficiency with semi-transparent material packed bed solar air heater. For total bed depth of $50 \mathrm{~mm}$, the percentage enhancement in thermal efficiency at lower $(0.01 \mathrm{~kg} / \mathrm{s})$ and higher mass flow rate $(0.06 \mathrm{~kg} / \mathrm{s})$ is found to be $78.6 \%$ - 62\%; $73.9 \%$ - 59.184\%; $62.5 \%$ $51.02 \%$; and $56.9 \%-47.704 \%$ with respect to plane collector for a bed of glass beads diameter of 3.4, 5.2, 10.0, and $12.5 \mathrm{~mm}$ respectively.

(vi) Effect of total bed depth on efficiency show that efficiency increases up to a certain total bed depth $(50 \mathrm{~mm})$ and there after found to fall rapidly.

(vii) It is found that for higher values of the temperature rise parameter, the effective efficiency values closely follow the thermal efficiency values, where as there is an appreciable difference in the lower range of air temperature rise parameter.

\section{Nomenclature}

$A_{c} \quad$ Collector plate area, $\mathrm{m}^{2}$

$A_{p} \quad$ Surface area of packing material, $\mathrm{m}^{2}$

$A_{f r} \quad$ Frontal area of collector bed, $\mathrm{m}^{2}$

$A_{v} \quad$ Surface area per unit volume, $\mathrm{m}^{-1}$

$A_{\text {void }} \quad$ Void area $(\rho A), \mathrm{m}^{2}$

$c_{p} \quad$ Specific heat of air, $\mathrm{Jkg}^{-1} \mathrm{~K}^{-1}$

$c_{s} \quad$ Specific heat of packing material, $\mathrm{Jkg}^{-1} \mathrm{~K}^{-1}$

$C_{f} \quad$ Conversion factor

$C_{m} \quad$ Equivalent temperature drop, ${ }^{\circ} \mathrm{C}$

$D \quad$ Depth of the channel, $\mathrm{m}$

$D_{p} \quad$ Diameter of glass beads

E Energy rate, $\mathrm{kW}$

Ex Exergy rate, $\mathrm{kW}$

$E x_{\text {dest }} \quad$ Rate of irreversibility, $\mathrm{kW}$

$G \quad$ Average mass velocity in matrix based on free flow area $\left(=m / p A_{f r}\right), \mathrm{kgs}^{-1} \mathrm{~m}^{-2}$

$h \quad$ Enthalpy, $\mathrm{kJkg}^{-1}$

$h_{c} \quad$ Convective heat transfer, $\mathrm{Wm}^{-2} \mathrm{~K}^{-1}$

$h_{r s} \quad$ Radiative heat transfer coefficient from solid surface to solid surface, $\mathrm{Wm}^{-2} \mathrm{~K}^{-1}$

$h_{r v} \quad$ Radiative heat transfer coefficient from void to void, $\mathrm{Wm}^{-2} \mathrm{~K}^{-1}$

$h_{v} \quad$ Volumetric heat transfer coefficient, $\mathrm{Wm}^{-3} \mathrm{~K}^{-1}$

$h_{w} \quad$ Wall heat transfer coefficient for glass cover, $\mathrm{Wm}^{-2} \mathrm{~K}^{-1}$

I Intensity of solar radiation, $\mathrm{Wm}^{-2}$

$I_{1} \quad$ Irradiation at the inner surface of glass cover, $\mathrm{Wm}^{-2}$

$I_{2} \quad$ Irradiation at the bottom plate of packed bed collector, $\mathrm{Wm}^{-2}$

$I_{y} \quad$ Intensity of solar radiation at depth y from upper surface of the bed, $\mathrm{Wm}^{-2}$

$k_{e} \quad$ Effective thermal conductivity of packed bed, $\mathrm{Wm}^{-1} \mathrm{~K}^{-1}$ $k_{g}, k_{s}$ Thermal conductivity of air, bed material respectively, $\mathrm{Wm}^{-1} \mathrm{~K}^{-1}$

$k_{\mathrm{e}}^{0} \quad$ Stagnant bed thermal conductivity, $\mathrm{Wm}^{-1} \mathrm{~K}^{-1}$

$L \quad$ Length of the channel, m

$L^{0} \quad$ Characteristic length of the channel, $\left[=D_{p}(p / 1-p)\right], \mathrm{m}$

$l_{v} \quad$ Effective thickness of fluid film in void, $\mathrm{m}$

$m \quad$ Mass flow rate of air, $\mathrm{kgs}^{-1}$

$n \quad$ Refractive index of packing

$\mathrm{Nu} \quad$ Nusselt number

$P \quad$ Fluid pressure, $\mathrm{Pa}$

$p \quad$ Porosity of the bed

$p_{m} \quad$ Mechanical power $\left(=m \Delta P / \rho \eta_{f a n}\right), \mathrm{W}$

$\triangle P \quad$ Pressure drop across collector duct, $\mathrm{Pa}$

$Q_{e} \quad$ Net energy gain, W

$Q_{s} \quad$ Incident energy in the collector area $\left[=I\left(\tau_{c} \alpha\right) A_{c}\right], \mathrm{kW}$

$Q_{u} \quad$ Useful heat gain. W

$Q_{r} \quad$ Radiative heat flux, $\mathrm{Wm}^{-2}$

$r_{c} \quad$ Reflectivity of glass cover

$R \quad$ Radiosity at the upper surface of glass cover, $\mathrm{Wm}^{-}$

$\dot{R} \quad$ Universal gas constant, $\mathrm{Jkg}^{-1} \mathrm{~K}^{-1}$

$R_{I} \quad$ Radiosity at the inner surface of glass cover, $\mathrm{Wm}^{-2}$

$R_{2} \quad$ Radiosity at the bottom plate, $\mathrm{Wm}^{-2}$

$R_{y} \quad$ Radiosity at a distance y from top surface, $\mathrm{Wm}^{-2}$

Re Reynolds number $\left(=4 \mathrm{r}_{H} \mathrm{G} / \mu\right)$

$S_{\text {gen }} \quad$ Entropy, $\mathrm{kJkg}^{-1} \mathrm{~K}^{-1}$

$T_{a} \quad$ Temperature of surrounding, ${ }^{\circ} \mathrm{C}$

$T_{b} \quad$ Temperature of bed, ${ }^{\circ} \mathrm{C}$

$T_{g} \quad$ Temperature of air, ${ }^{\circ} \mathrm{C}$

$T_{p} \quad$ Temperature of packed material, ${ }^{\circ} \mathrm{C}$

$T_{c} \quad$ Temperature of glass cover, ${ }^{\circ} \mathrm{C}$

$T_{i}, T_{o} \quad$ Inlet and outlet temperature of air respectively, ${ }^{\circ} \mathrm{C}$

$T_{s} \quad$ Temperature of sun, $\mathrm{K}$

$\Delta T$

$\bar{u}$

$u^{0}$

Air temperature rise $\left(=T_{o}-T_{i}\right),{ }^{o} \mathrm{C}$

Flow velocity in duct, $\mathrm{ms}^{-1}$

Characteristic velocity, $\mathrm{ms}^{-1}$

$U_{L}$

Overall loss coefficient, $\mathrm{Wm}^{-2} \mathrm{~K}^{-1}$

$\bar{v}_{x} \quad$ Average velocity of the fluid flow in void space, $\mathrm{ms}^{-1}$

$V \quad$ Superficial mean gas velocity $(=G / \rho), \mathrm{ms}^{-1}$

$V_{p} \quad$ Volume of packing material, $\mathrm{m}^{3}$

$W \quad$ Width of the channel, $\mathrm{m}$

$x \quad$ Distance in horizontal direction from inlet, $\mathrm{m}$

$\bar{x} \quad$ Non-dimensional distance $(=x / L)$

$\Delta \bar{x} \quad$ Non-dimensional elemental thickness in $\mathrm{x}$ direction

$y \quad$ Distance in vertical direction from top surface, $\mathrm{m}$ 
[9] Y. H. Hamid, and W. A. Beckman, "Performance of aircooled radioactivity heated screen matrices,"Trans. ASME, J. Engineering for Power, 221-224, 1971.

\section{Greek symbols}

$\eta_{\text {th }} \quad$ Thermal efficiency

$\eta_{\text {eff }} \quad$ Effective efficiency

$\eta_{I I} \quad$ Exergetic efficiency

$\alpha \quad$ Absorptivity of glass beads

$\alpha_{c} \quad$ Absorptivity of glass cover

$\tau \quad$ Optical depth

$\tau_{c} \quad$ Transmissivity of glass cover

$\tau_{0} \quad$ Optical depth at $\mathrm{y}=\mathrm{D}(=\beta \mathrm{D})$

$\Delta \tau$ Non-dimensional elemental thickness in $\mathrm{y}$ direction

$\rho, \rho_{s}$ Density of air and packing material respectively, $\mathrm{kgm}^{-3}$

$\rho_{c} \quad$ Reflectivity of glass cover

$\sigma \quad$ Stefan-Boltzmann constant

$\beta \quad$ Extinction coefficient of matrix, $\mathrm{m}^{-1}$

$\varepsilon \quad$ Emissivity of solid surface

$\varepsilon_{w} \quad$ Emissivity of bottom plate

$\psi \quad$ Specific exergy, $\mathrm{kJkg}^{-1}$

$\varphi \quad$ Angle factor i.e. the ratio of effective thickness of fluid film in the void in relation to thermal conduction to diameter of packing material $\left(=l_{v} / D_{p}\right)$

$\mu \quad$ Dynamic viscosity of fluid, $\mathrm{Nsm}^{-2}$

\section{Subscript \\ in Inlet \\ out Outlet}

\section{References}

[1] J. E. Coppage, and A. L. London, "Heat transfer and flow friction characteristics of porous media,"Chem. Engg. Progress, 52, 57F-63F, 1956.

[2] L. S. Tong, and A. L. London, "Heat transfer and flow friction characteristics of woven-screen and cross-rod matrices,"Trans. ASME, 79, 1558-1570, 1957.

[3] R. Viskanta, "Radiation transfer and interaction of convection with radiation heat transfer, in Thomas F. Irvine, Jr., and James P. Harnett (cds.)," Advances in Heat Transfer, 3,175-251, 1966.

[4] S. Whitaker, "Forced convection heat transfer correlations for flow in pipes, past flat plates, single cylinders, single spheres and for flow in packed beds and tube bundles,"AIChEJ, 18, 361-371, 1972.

[5] J. P. Chiou, M. M. El-Wakil, and J. A. Duffie, "A slit and expanded aluminum foil matrix solar collector,"Solar Energy, 9, 73-80, 1965.

[6] J. P. Chiou, M. M. El-Wakil,"Heat transfer and flow characteristics of porous matrices with radiation as heat source,"Trans. of ASME, J. Heat Transfer, 2, 69-76, 1966.

[7] M. J. Shoemaker, "Notes on a solar collector with unique air permeable media,"Solar Energy, 5, 138-141, 1961.

[8] W. A. Beckmann, "Radiation and convection heat transfer in a porous-bed,"Trans. ASME, J. of Engineering for Power, 90, 51-54, 1968.
[10] R. K. Swartman, and O. Ogunade, "An investigation on packed bed collectors,"Solar Energy, 10, 106-110, 1966.

[11] S. C. Gupta, "Effectiveness of packed-bed solar air heaters,"Solar Energy Int. Progress, Proc. of the Int. Symposium-workshop on Solar Energy, 2, Cairo, Egypt, pp. 767-777, 1978.

[12] P. Singh, "Cheap packed bed absorbers for solar air heaters,"Proc. Int. Solar Energy Society, New Delhi, 2, 900-904, 1978.

[13] C. B. Mishra, and S. P. Sharma, "Performance study of air-heated packed-bed solar energy collectors,"Int. J. of Energy, 6,153-157, 1981.

[14] R. K. Collier, "The characterization of crushed glass as a transpired air heating solar collector material,"Proc. of Int. Solar Energy Society, Atlanta, Georgia, 264-268, 1979.

[15] M. Hastani, Y. Itaya, and K. Adachi, "Heat transfer and thermal storage characteristics of optically semitransparent material packed-bed solar air heaters,"Current Research in HMT, I.I.T. Madras, India, 61-70, 1985.

[16] Y. Demirel, S. Kunc, "Thermal performance study on a solar air heater with packed flow passage,"Energy Conversion and Management, 27, 317-325, 1987.

[17] Y. Demirel, "Experimental investigation of heat transfer in a packed duct with unequal wall temperatures,"Experimental Thermal and Fluid Science, 2, 425-430, 1989.

[18] Y. Demirel, B. A. Abu-Al-Saud, H. H. Al-Ali, Y. Makkawi, "Packing size and shape effects on forced convection in large rectangular packed ducts with asymmetric heating,"International Journal of Heat and Mass Transfer, 42, 3267-3277, 1999.

[19] H. H. Ozturk, A. Bascetincelik, Y. Demirel, H. O. Paksoy, "Dolgulutoplaclarinisilanalizi,"Proceedings of Sun Day Symposium 99, Kayseri, Turkey. pp.43-46, 1999.

[20] Y. Demirel, R. Kahraman, "Entropy generation in a rectangular packed duct with a wall heat flux,"International Journal of Heat and Mass Transfer, 42, 2337-2344, 1999.

[21] S. P. Sharma, J. S. Saini, and H. K. Varma, "Thermal performance of packed-bed solar air heaters,"Solar Energy, 47, 59-67, 1991.

[22] C. Choudhary and H. P. Garg,"Performance of airheating collectors with packed airflow passage,"Solar Energy, 50, 205-221, 1993.

[23] H. H. Ozturk, and Y. Demirel, "Energy-based performance analysis of packed bed solar air heaters,"Int. J. Energy Res., 28, 423-432, 2004.

[24] J. Tian, T. Kim, T. J. Lu, H. P.Hodson, D. T. Queheillalt, D. J. Sypeck, and H. N. G. Wadley, "The effects of topology upon fluid flow and heat transfer within cellular copper structures,"Int. J. HMT, 47, 31713186, 2004.

[25] L. Varshney, and J. S. Saini, "Heat transfer and friction factor correlations for rectangular solar air heater duct packed with wire mesh screen matrices,"Solar Energy, 62(4), 255-262, 1998.

[26] N. S. Thakur, J. S. Sainiand S. C. Solanki, "Heat transfer and friction factor correlations for packed bed 
solar air heater for a low porosity system,"Solar Energy, 74, 319-329, 2003.

[27] S. B. Prasad, J. S. Saini, and K. M. Singh, "Investigation of heat transfer and friction characteristics of packed bed solar air heater using wire mesh as packing material,"Solar Energy, 83,773-783, 2009.

[28] L. B. Y. Aldabbagh, F. Egelioglu, and M. Ilkan, "Single and double pass solar air heaters with wire mesh as packing bed," Energy, 35, 3783-3787, 2010.

[29] P. Dhiman, N. S. Thakur, and S. R. Chauhan, "Thermal and thermohydraulic performance of counter and parallel flow packed bed solar air heaters,"Renewable Energy, 46, 259-268, 2012.

[30] P. Verma, L. Varshney, "Parametric investigation on thermo-hydraulic performance of wire screen matrix packed solar air heater,"Sustainable Energy Technologies and Assessments, 10, 40-52, 2015.

[31] V. K. Chouksey, and S. P. Sharma, "Investigations on thermal performance characteristics of wire screen packed bed solar air heater,"Solar Energy, 132, 591605, 2016.

[32] S. Yagi, and D. Kunii, "Studies on effective thermal conductivities in packed beds,"AIChE. J., 3(3), 373-381, 1957.

[33] H. Esen, "Experimental energy and exergy analysis of a double-flow solar air heater having different obstacles on absorber plates,"Build Environ, 43, 1046-1054, 2008.

[34] J. A. Duffie, and W. A. Beckman, Solar Energy Thermal Processes, Wiley, New York, 1980.

[35] D. Kunii, and J. M. Smith, "Heat Transfer Characteristics of Porous Rocks,"AIChE. J., 6, 71, 1960. 